\title{
Identification of Three Phase IPM Machine Parameters Using Torque Tests
}

\author{
S. A. Odhano, Member IEEE R. \\ Bojoi, Senior Member IEEE \\ E. Armando, Member IEEE \\ Politecnico di Torino \\ Corso Duca degli Abruzzi, 24 \\ Turin, 10129, Italy \\ shafiq.odhano@polito.it \\ radu.bojoi@polito.it \\ eric.armando@polito.it
}

\author{
Guilherme Homrich \\ Aly Ferreira Flores Filho \\ Post-graduate Programme in \\ Electrical Engineering \\ Federal University of Rio Grande do Sul \\ Porto Alegre, RS 90.035-190, Brazil \\ Ghomrich28@gmail.com \\ aly.flores@ufrgs.br
}

\author{
Mircea Popescu, Fellow IEEE \\ Motor Design Limited \\ Ellesmere, UK \\ Mircea.Popescu@motor-design.com \\ D. G. Dorrell, Senior Member IEEE \\ University of Technology Sydney \\ Broadway, Sydney, NSW 2007, Australia \\ d.g.dorrell@gmail.com
}

\begin{abstract}
This work presents a simple method for obtaining the main parameters, such as the torque constant and the $d$ - and $q$-axis inductances $L_{d}$ and $L_{q}$, for a brushless internal permanent magnet motor by measuring the machine torque during testing. These tests are relatively simple to carry out compared to other test procedures described in the literature and do not require sophisticated and expensive test equipment nor they are affected by temperature effects as happens with other techniques. The machine under test is supplied through a dc supply at different rotor positions. The shaft torque is measured through a torque sensor during the tests. The test current magnitude is varied to take care of the saturation effects. From the measured torque data and known rotor position, the required parameters can be obtained. Tests performed on two different internal permanent magnet machines confirm the validity and effectiveness of the proposed method.
\end{abstract}

Keywords - inductance measurement, non-linear magnetics, parameter estimation, permanent magnet machines, torque measurement

\section{INTRODUCTION}

Parameter computation, identification and estimation of permanent magnet (PM) machines have been the focus of study for the past few decades [1-3]. The subject has been further studied with recent works $[4,5]$. Some of the studies carried out so far are quite in-depth in terms analyzing magnetization and losses [6, 7]. The literature reports parameter computation methods that are based on finite element analysis [8] as well as some on-line parameter estimation algorithms [9-11]. These are tailored for high performance and sensorless control schemes.

In terms of their operation, the PM machines are classified as either DC or AC brushless [12]; in the latter case, standard synchronous machine theory is applicable [13]. More recently, they can also be AC voltage controlled machines with the advent of line-start permanent magnet machines. With variable frequency drives, the PM machines are best known for their high dynamic performance. High performance and efficient control, however, is only possible when the machine parameters are known with reasonable accuracy. These parameters can vary between different machines of the same production batch due to manufacturing tolerances and variances. These parameter variations may not be negligible. For the drive, the connected electrical machine is often an effective black box and its parameters are not known because the geometrical and electromagnetic details of the machine are unknown. Moreover, the machine parameters depend also on its environment (e.g. temperature) or the operating conditions (e.g. saturation). For instance, the stator resistance and the PM flux-linkage experience significant changes with temperature.

The design and manufacture of PM machines often follow the requirements set out by specific end-use applications. Machines of varied characteristics are constructed as a result of such requirements, even if they fall into a narrow power and speed range. Therefore, a general catalogue that lists parameters for different machines of a given power range would be of little use when it comes to knowing the characteristics of various machines with a good degree of accuracy. Dedicated testing is therefore necessary for precise parameter identification of a given machine to accurately tune the controllers for high performance control in a given application.

The available literature on parameter identification of PM machines give a number studies that explore methods for determining PM machine parameters. The techniques investigated in the literature estimate machine parameters either analytically (from the design data) or through experimental tests. A brief survey of different parameter identification methodologies can be found in [14].

Most of the methods found in the literature make use of a complete drive setup for machine parameter identification. For instance, [4] identifies the flux characteristics for synchronous reluctance and interior permanent magnet (IPM) machines at standstill using a commercial drive with modified software. The flux characteristic is approximated as a function of current and the coefficients of this function are obtained through multiple linear regression. The test machines are injected with voltage signals and the current response is analyzed for 
constructing the flux characteristics. It must be noted that if the machine parameters are not known, the voltage signal application in open-loop may trigger overcurrent protection. A different approach is proposed in [15] that again needs an entire drive system along with a prime mover that turns the shaft at constant speed. The machine under test is supplied with different current vectors, using high bandwidth current controllers, in the rotor $d q$ synchronous frame, and the fluxcurrent relationship for the $d$ - and $q$-axis, collectively known as the magnetic model, are identified. Another identification method proposed in [16] that requires a complete drive is based on a least squares algorithm. The algorithm estimates machine parameter at a single operating point, which overlooks magnetic saturation and cross-magnetizing saturation effects that are often encountered in PM machines. The identification strategy proposed in [17] determines machine inductances at a single magnetic operating point. The inductances are then assumed constant for the entire operating range; however, the inductances do vary with current, which is in fact highlighted in this paper, as well as in other works previously cited. A self-commissioning scheme for IPM motor drive parameter identification is detailed in [18]. This study necessitates the availability of a complete drive setup so that tests can be carried out. The machine is injected with a highfrequency current of varying amplitudes on its $d$ - and $q$-axes to estimate the inductances on these axes, and subsequently the flux-linkages; thus, defining the complete magnetic model. Another self-commissioning scheme [19] used a dc-biased ac injection technique that again defines the complete magnetic model of the machine; however, the need for a complete drive system remains.

The literature on the subject also reports studies that proposed test strategies that do not require a power converter, as documented in [20] as well as in several other papers.

The present work puts forward and experimentally validates a simple test strategy that does not require a complete drive to get PM machine parameters [21]. The set of simple tests proposed here can characterize the machine with little expertise required on part of the commissioning staff. The test procedure devised here is carried out through a dc supply that applies and maintains a constant current in the test machine. The machine under test is mechanically coupled, through a torque sensor, to a prime mover that rotates it at a controlled constant speed during the tests. Although the prime mover is not strictly needed as the tests can be conducted with blocked rotor at two different rotor positions, it is used for open circuit tests for validation of permanent magnet flux-linkage results as well as to conduct a short-circuit test at low-speed. The torque sensor readings are taken for different rotor positions. With simple calculations, the PM flux-linkages and $d$-, $q$-axis inductances can be obtained. The tests are performed at different current levels to take into account magnetic saturation effects. The method is not influenced by stator resistance variations due to temperature as happens in other schemes, such as [15]. The complication of dealing with inverter non-linearity effects is also ruled out even if the tests are carried through the inverter, as will be shown in the results.

\section{BACKGROUND AND ANALYSIS}

The parameter extraction method put forward here is similar to that investigated in [22]. However, here the focus is on PM machines designed for use with power electronics drives rather than line-start permanent magnet machines of [22].

The torque produced by an internal permanent magnet (IPM) machine has two components: the magnet alignment torque and the reluctance torque. Depending on the flux produced by permanent magnets used and the anisotropy of the machine, the contribution of each torque component towards the total torque is decided at the design stage. The total torque of a three-phase PM machine in terms of $d$ - and $q$-axis current components of the phase current can be written as:

$$
T_{e}=3 p\left\{\lambda_{m} i_{q}+\left(L_{d}-L_{q}\right) i_{d} i_{q}\right\}
$$

where $p$ is the machine pole-pair number, $\lambda_{m}$ is the fluxlinkage of the permanent magnets with a phase winding, and $i_{d}$ and $i_{q}$ are the $d$ - and $q$-axis current components of the phase currents (in rms), respectively. Fig. 1 (a) gives the definition of machine $d q$-axes. As the convention of PM machines is adopted here with the $d$-axis aligned to the north pole of permanent magnets, the reluctance torque component is positive only when $i_{d}<0$ ( since $L_{d}<L_{q}$ ).

With a given phase current magnitude, the net torque depends on the position of current vector with respect to the north pole of the rotor permanent magnets (or equivalently with respect to the induced emf in the time domain). Fig. 1 (b) shows the position of current vector in $d q$-plane. The vector subtends an angle $\gamma$ with respect to the $q$-axis. The torque equation in (1) can also be written in terms of this angle $\gamma$ such that:

$$
T_{e}=3 p\left\{\lambda_{m} I_{p h} \cos (\gamma)+\frac{\left(L_{q}-L_{d}\right)}{2} I_{p h}^{2} \sin (2 \gamma)\right\}
$$

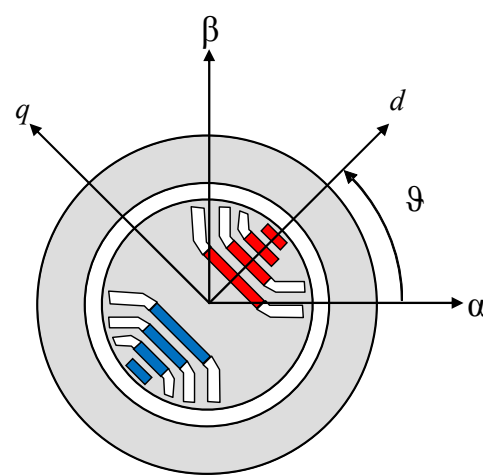

(a)

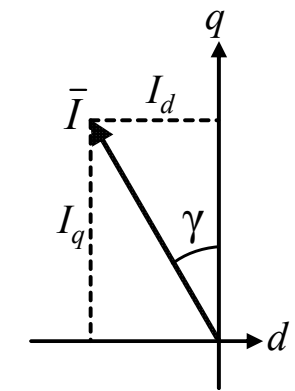

(b)
Fig. 1. (a) dq frame definition, (b) definition of angle $\gamma$ where $I$ is the rms phase current. 
This can be rewritten in terms of two constants $A$ and $R$ and the angle $\gamma$. This gives

$$
T_{e}=A \cos (\gamma)+R \sin (2 \gamma)
$$

where $A$ stands for alignment and $R$ for anisotropy (or reluctance) and are defined by comparing (3) with (2) as:

$$
A=3 p \lambda_{m} I_{p h} \quad \text { and } \quad R=\frac{3}{2} p\left(L_{q}-L_{d}\right) I_{p h}^{2}
$$

In (3) there are two unknowns in one equation. Therefore, if two static tests are performed with the same phase current but different rotor angles (i.e. two different values for $\gamma$ of Fig. 1 (b)), the constants $A$ and $R$ can be computed. That is:

$$
\begin{aligned}
& T_{e 1}=A \cos \left(\gamma_{1}\right)+R \sin \left(2 \gamma_{1}\right) \\
& T_{e 2}=A \cos \left(\gamma_{2}\right)+R \sin \left(2 \gamma_{2}\right)
\end{aligned}
$$

Solving (5) for $A$ and $R$, we have:

$$
\begin{aligned}
& A=\frac{T_{e 1} \sin \left(2 \gamma_{2}\right)-T_{e 2} \sin \left(2 \gamma_{1}\right)}{\cos \left(\gamma_{1}\right) \sin \left(2 \gamma_{2}\right)-\cos \left(\gamma_{2}\right) \sin \left(2 \gamma_{1}\right)} \\
& R=\frac{T_{e 2} \cos \left(\gamma_{1}\right)-T_{e 1} \cos \left(\gamma_{2}\right)}{\cos \left(\gamma_{1}\right) \sin \left(2 \gamma_{2}\right)-\cos \left(\gamma_{2}\right) \sin \left(2 \gamma_{1}\right)}
\end{aligned}
$$

The equation for $R$ is corrected from that in [22]. Further, from these two values of $A$ and $R$ given by (6), the PM flux linkage $\left(\lambda_{m}\right)$ and the difference between the $d$ - and $q$-axis inductances can be found using (4) so that:

$$
\begin{aligned}
& \lambda_{m}=\frac{A}{3 p I_{p h}} \\
& L_{q}-L_{d}=\frac{2 R}{3 p I_{p h}^{2}}
\end{aligned}
$$

It can be argued that the flux-linkage due to permanent magnets depends on $d$ - and $q$-axis stator currents, i.e. on the angle $\gamma$, but this dependence is negligibly small compared to the effects due to temperature rise. The PM flux-linkage $\left(\lambda_{m}\right)$ does not undergo any significant change as function of current even for machines having very high anisotropy ratios. For instance, the analysis presented in [23] in which two highly anisotropic machines with very small PM flux contribution were studied, the flux linked with the stator windings due to permanent magnets showed very minute variation with respect to current in the stator. The results presented for the curve $\lambda_{q}\left(i_{d}, 0\right)$ show negligible variation in $q$-axis flux (which at $\left.i_{q}=0\right)$ is entirely due to permanent magnets. Note that the convention used in the above article is based on synchronous reluctance machines in which the PM flux-linkage is directed along the negative $q$-axis. Whereas in the present work the PM machine convention is used for which the PM flux is along the positive d-axis (Fig. 1 (a)). The authors in [23] qualitatively commented that the change in linked flux is due to the fact that, as the stator current saturates the rotor ribs, the PM-flux follows the low reluctance path to link with stator windings, hence an enhanced flux with $i_{d} \neq 0$. Based on these analysis, it can be safely assumed that the PM flux change with the stator current magnitude and angle $\gamma$ is negligible.

As far as the $d$ - and $q$-axis inductances, and their difference, in a PM machine are concerned, their dependence on the current magnitude due to saturation and current angle $\gamma$ due to cross-saturation cannot be ignored. To take into account these effects, it is possible to conduct several tests at different current levels (by varying $I_{p h}$ ) and different values of $\gamma$. Varying the test current $I_{p h}$ from a minimum value up to the rated machine current will allow the analysis of the magnetic saturation effects. For each test current magnitude, the angle $\gamma$ can vary between 0 and $90^{\circ}$. This allows the tracing of the entire $d q$-plane at a given current magnitude (cf. Fig. 1 (b)). This is for a motor, for a generator the current will lie around the negative $q$-axis. Therefore, the effects of cross-saturation between the two axes can also be quantified, albeit approximately. However, it must be noted that for machines with high saliency ratios and small PM flux, the inductances vary a great deal with the $d$ - and $q$-axis currents [23], thus the application of this technique needs careful consideration with such machines.

However, with these tests, only the difference between $L_{d}$ and $L_{q}$ can be obtained. To separate the two, a short-circuit test can be conducted that gives the machine $d$-axis inductance. The machine is rotated at a speed at which the short-circuit current does not exceed the rated machine current. When the winding is in short circuit, the phasor diagram of Fig. 2 holds good.

Under short circuit conditions, if the resistance is negligible, compared to inductive reactance, the current is aligned to the $d$-axis so that:

$$
\begin{gathered}
X_{d}=\frac{E_{q}}{I_{d}}=\frac{\omega \lambda_{m}}{I_{p h}} \quad \because I_{d} \equiv I_{p h} \\
\omega L_{d}=\frac{\omega \lambda_{m}}{I_{p h}} \Rightarrow L_{d}=\frac{\lambda_{m}}{I_{p h}}
\end{gathered}
$$

If this test is also conducted at different short-circuit currents, the inductance $L_{d}$ can be obtained as a function of current. This can be used in (7) to get $L_{q}$.

If the resistance of the machine is not negligible and must be considered, the short-circuit test can be conducted through a wattmeter on the same lines as for an induction machine [24].

An improvement for the short circuit test is to add additional reactances to the short circuit in order to limit the current. This is reported in IEEE Standard 1812 [25]. This means that, for additional added per-phase inductance $L_{e x}$

$$
L_{d}=\frac{\lambda_{m}}{I_{p h}}-L_{e x}
$$


Care must be taken that $L_{e x}$ does not saturate for the entire test current range lest the calculation of $L_{d}$ through (10) gives erroneous results.

An open circuit test can also be carried out to validate the magnet flux linkage using (8).

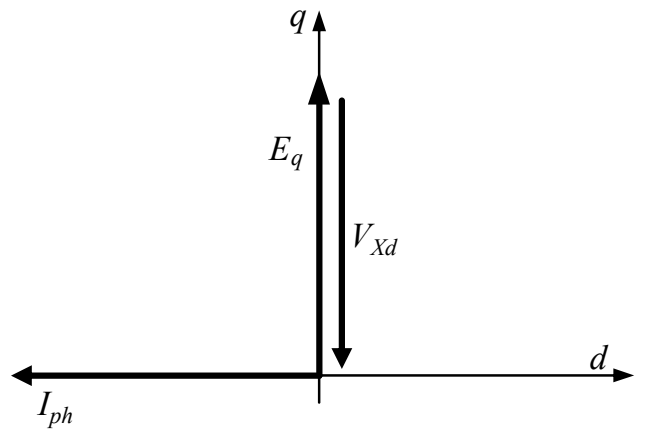

Fig. 2. Short circuit phasor diagram.

\section{IMPLEMENTATION AND EXPERIMENTAL SETUP}

The method proposed here is validated experimentally on two different interior permanent magnet (IPM) synchronous machines. The data are given in Table I for the two machines. The parameters are nominal and were obtained from various simulations and tests.

The first machine is a $7.5 \mathrm{~kW}$, 4-pole light traction motor with four flux barriers as shown in its cross-section in Fig. 3 [15]. The machine has substantial saliency as the $d$ - and $q$-axis inductances are in the ratio of 1:10.

The second test machine is again an IPM having eight poles and a rated power of $1.5 \mathrm{~kW}$. The end-use of this machine is meant to be as a variable speed PM generator. The rotor crosssection is shown in Fig. 4. It can be seen from Table I that this machine does have some saliency although it is not as pronounced as for the first test machine.

The first machine, IPM-I, has an anisotropy of 1:10 and it exhibits significant cross-saturation effects. In the total electromagnetic torque developed, the reluctance torque component is dominant $(\sim 85 \%)$ over the magnet alignment part. As the machine is designed for traction applications, it is meant to reach relatively high speeds (in flux-weakening) so the anisotropy is purposefully kept high.

For the second machine, IPM-II, the spoke type rotor contains deeply buried magnets with flux barriers along the $q$-axis. The anisotropy ratio is limited and the major contribution for the torque comes from the permanent magnets.

TABLE I. MACHINE DATA

\begin{tabular}{|l|l|l|c|}
\hline \multicolumn{4}{|c|}{ Machine Data } \\
\hline \multicolumn{1}{|c|}{ Quantity } & Unit & IPM-I & IPM-II \\
\hline Rated power & $\mathrm{kW}$ & 7.5 & 1.5 \\
\hline Rated current & $\mathrm{A}_{\mathrm{pk}}$ & 35 & 4.54 \\
\hline Pole-pairs & -- & 2 & 4 \\
\hline Rated speed & $\mathrm{rpm}$ & 2,450 & 120 \\
\hline Max. speed & $\mathrm{rpm}$ & 10,000 & 900 \\
\hline$R_{s}$ & $\Omega$ & 0.3 & 3.25 \\
\hline$L_{d}$ (unsaturated) & $\mathrm{mH}$ & 4 & 80 \\
\hline
\end{tabular}

\begin{tabular}{|l|l|l|l|}
\hline$L_{q}$ (unsaturated) & $\mathrm{mH}$ & 40 & 140 \\
\hline$\lambda_{m}$ & $\mathrm{Vs}$ & 0.064 & 0.54 \\
\hline
\end{tabular}

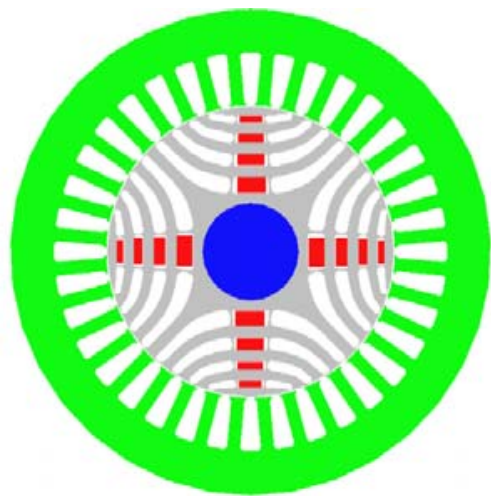

Fig. 3. Test machine 1: stator and rotor structure [11].

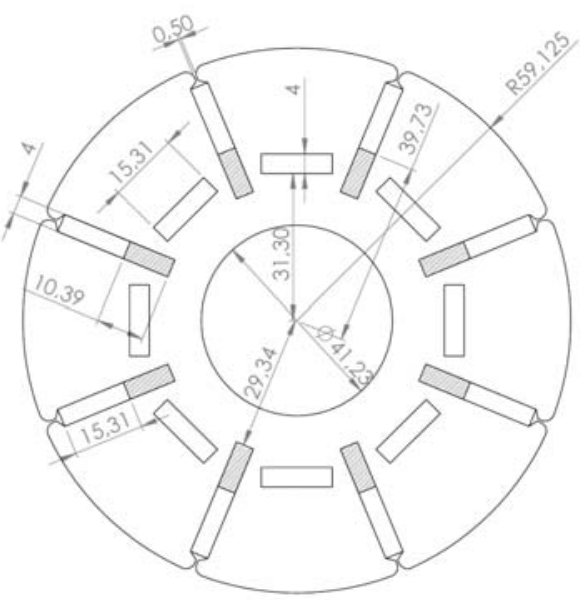

Fig. 4. Test machine 2: rotor geometry.

Along with the machines under test, the test setups consist of a dc supply, current acquisition system, and a torque sensor. For obtaining precise results, a rotor position sensor is also included that provides rotor position information during the tests. The position sensor is a low-cost incremental encoder with a resolution of 512 pulses/revolution. For conducting the tests at standstill at different $\gamma$ values, the rotor needs to be blocked mechanically downstream of the torque sensor. The rotor locking can also be achieved through the prime mover employed for short-circuit tests by controlling it in speed control mode and requesting zero reference speed. However, the readings on the torque sensor be taken after the oscillations die down and steady state condition is reached when changing $\gamma$ values.

For the short-circuit test, which is needed to obtain $L_{d}$, a prime mover would also be required and this needs to be able to run slowly and provide sufficient torque to overcome the short-circuited machine's mechanical resistance.

Since the rotor position information is continuously available, the PM flux-linkage $\left(\lambda_{m}\right)$ can also be obtained by reading the torque sensor output precisely when the rotor angle is $90^{\circ}$ (electrical) from the $d$-axis. At this point the $d$-axis current component is zero, so is the reluctance torque 
component. The total torque is now given only by the magnet alignment component. Fig. 5 gives the total torque and its constituent components for a given current magnitude and different current vector angles $(\gamma)$ for an anisotropic PM machine. This is for a machine that has $q$-axis saliency such as the first test machine. At $\gamma=0^{\circ}$, the following equation holds:

$$
T_{e}=3 p \lambda_{m} i_{q}=3 p \lambda_{m} I_{p h} \quad \Rightarrow \quad \lambda_{m}=\frac{T_{e}}{3 p I_{p h}}
$$

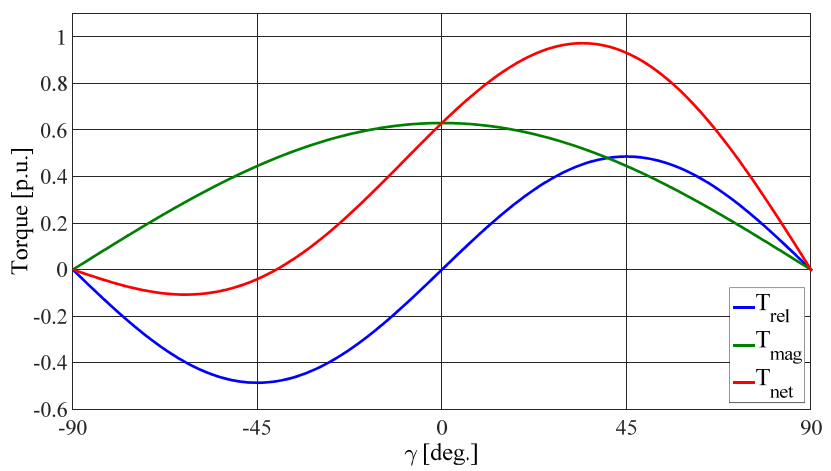

Fig. 5. Torque components for an anisotropic PM machine as a function of current angle $(\gamma): T_{\text {rel }}=$ reluctance component, $T_{m a g}=$ magnet alignment torque, $T_{n e t}=$ total torque

Equation (11) provides a crosscheck for the value of PM flux-linkage obtained from (7), thus avoiding possible computation errors. Besides, (11) can also be used to verify the impact of phase current variations on the PM flux-linkage, which has been stated above as being negligibly small. If the machine has $d$-axis saliency then the reluctance torque in Fig. 5 is inverted so that the total torque peak is between -90 and 0 degrees.

\section{EXPERIMENTAL RESULTS}

Referring to (6), only two tests for each current level are required where the angle $\gamma$ assumes two distinct values (namely $\gamma_{1}$ and $\gamma_{2}$ ). However, the tests are performed by observing the torque evolution throughout a complete revolution. This section is divided two parts: the first test machine and second test machine tests. During these tests both machines were star connected with dc current injected into one phase and exiting through the parallel connected other two phases. These results complement results for a line-start PM machine put forward in [22].

\section{A. First test machine}

Fig. 6 gives the measured torque as a function of rotor electrical angle while a constant current is maintained in the winding from a dc supply. It is important to note that the rotor electrical angle is $90^{\circ}$ behind the angle $\gamma$ of Fig. 1(b). Fig. 6 in terms of angle $\gamma$ is drawn in Fig. 7 for a quick comparison with Fig. 5. It is evident that for $\gamma<0^{\circ}$, i.e. $i_{d}>0$, the torque diminishes and it is true for all anisotropic machines. These machines are operated with negative $d$-axis current for this obvious reason. Therefore, the $d$-axis inductance values of negative $i_{d}$ are of interest.
For verification of the obtained results, the same tests are also performed through a power converter by implementing a current control that injects a constant current in the machine while it is rotated through the prime mover. Fig. 8 gives results from IPM-I when the rated machine current $(35 \mathrm{~A})$ is applied. It is opportune to note here that the use of power converter does not necessarily mean that all the problems related to the inverter non-linearity effects are present also here. Since the method does not rely on the voltage applied to the machine, the problems related to voltage reconstruction are completely excluded, so the need for compensating for inverter error is also eliminated. Furthermore, the stator resistance increase due to temperature is also excluded from affecting the results as the parameter values depend only on the measured torque that is inherently independent of stator resistance. However, the need of having a precise torque sensor for the tests can be an additional requirement of the proposed method as it is not required by other methods, such as [15].

Fig. 9 shows the estimated difference between the $d$ - and $q$-axis inductances as a function of applied current. The saturation effects are evident at high current levels since the decrement in $L_{q}$ is more than that in $L_{d}$, the difference between the two decreases with current. In Fig. 10, the permanent magnet flux-linkage estimation results are compared with the reference value.

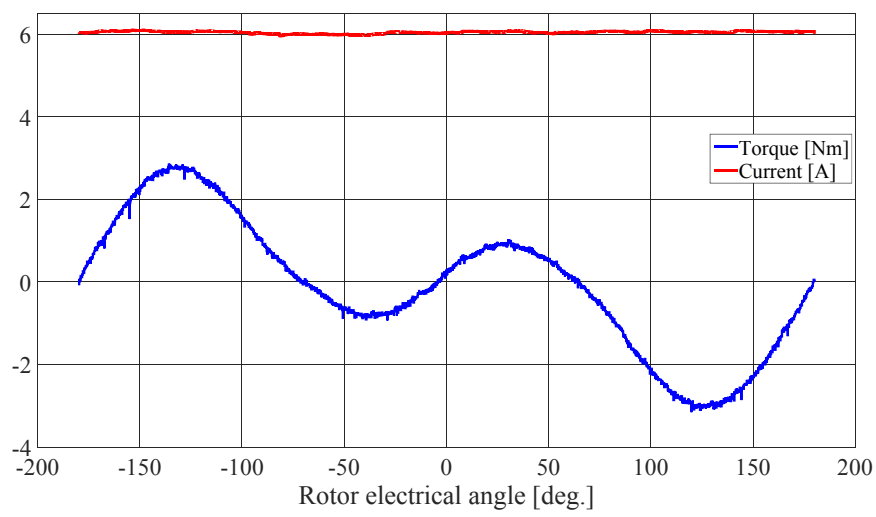

Fig. 6. Measured torque as a function of rotor electrical angle with a constant current maintained by a dc supply.

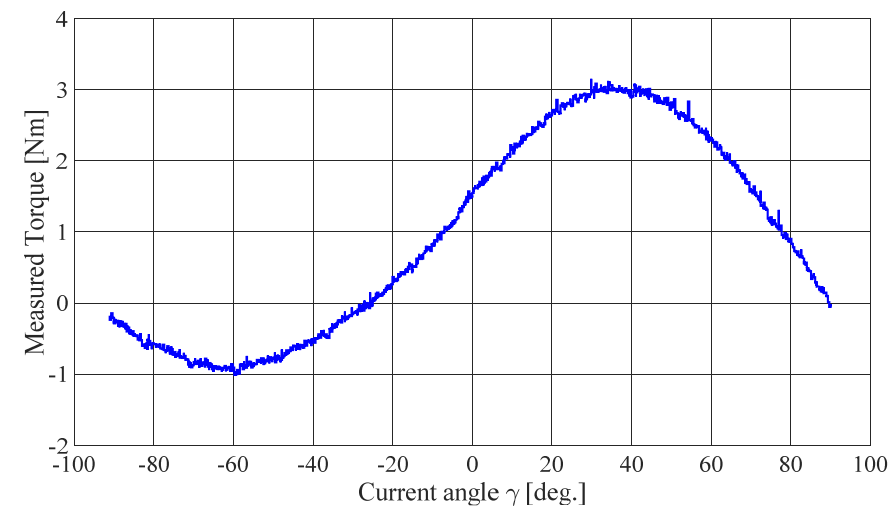

Fig. 7. Measured torque of Fig. 6 replotted as a function of current angle $(\gamma)$ with a constant current maintained by a dc supply. 


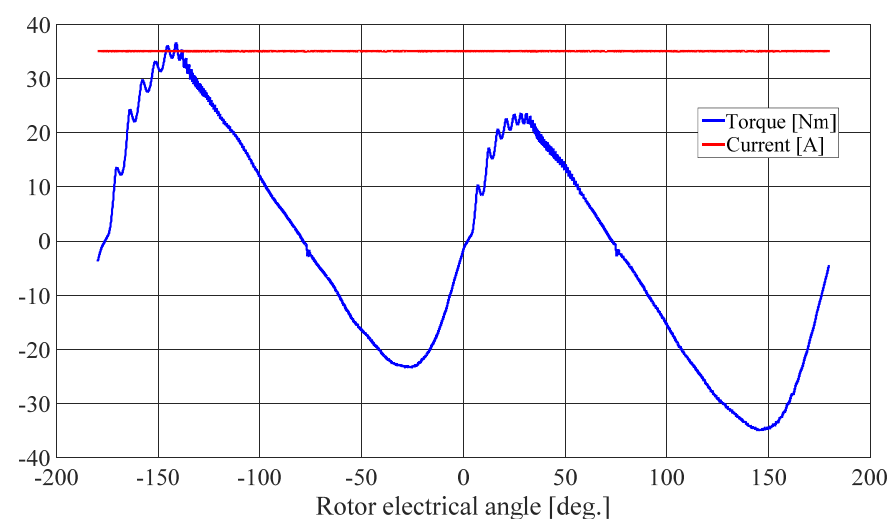

Fig. 8. Test with a power converter: measured torque as a function of rotor electrical angle when the machine's rated current is injected.

The figures 9 and 10 contain results obtained with the dc supply as well as those obtained using the power converter. Fig. 11 gives the results from a short-circuit test and this illustrates the saturation effects with $L_{d}$ decreasing with increasing current.

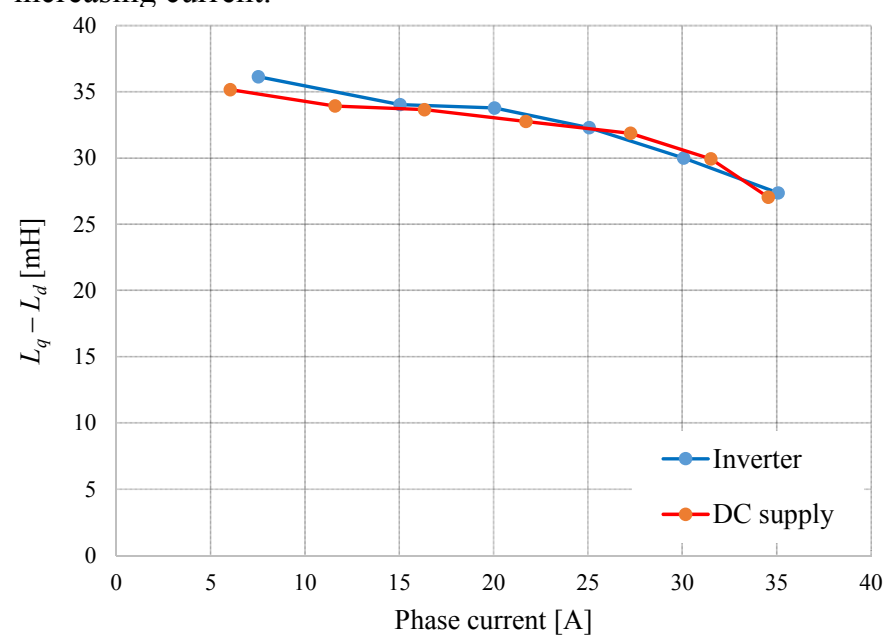

Fig. 9. Results for inductance difference as a function of phase current: results obtained with dc supply and power converter.

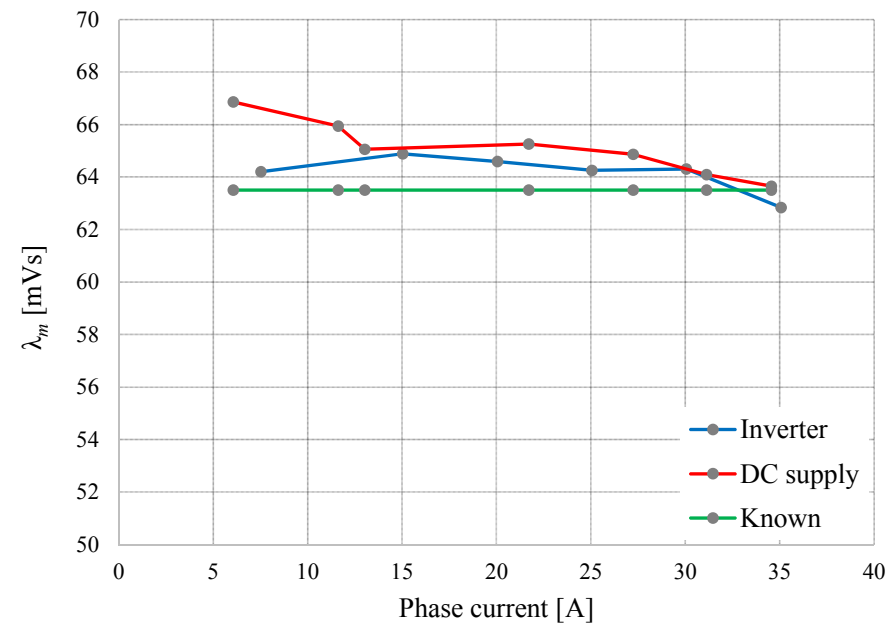

Fig. 10. Permanent magnet flux-linkage computation using (11): results comparison for tests with inverter and dc supply.

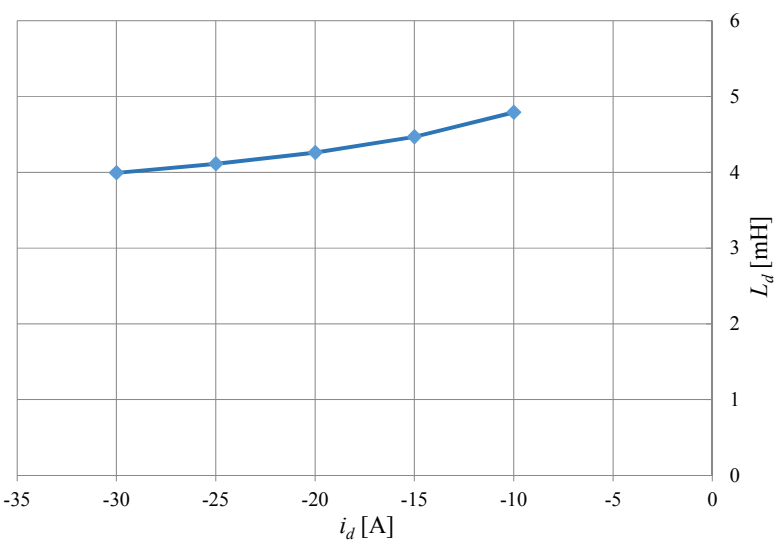

Fig. 11. $d$-axis inductance as a function of current.

\section{B. Second test machine}

Fig. 12 gives the test set-up for this machine (on the left). It is matched against a prime mover because its primary role is as a generator. There is also a torque transducer fitted which allowed the dc test to be carried out easily.

In Fig. 13, a set of results are put forward for different dc current levels. Because current is injected into one phase and exits through the other two in parallel then this represents a point in time where the current is peaking in one phase. Therefore $I_{p h}(\mathrm{rms})=I_{d c} / \sqrt{ } 2$. It can be seen that the torque is maximum at about $22 \mathrm{deg}$. elec. which illustrates that this machine has $q$-axis saliency but it is not highly salient as is the case with the first test machine.

From the results in Fig. 13 then the $L_{q}-L_{d}$ values and the flux linkage $\lambda_{m}$ can be calculated from (7). It can be seen that there are many points to choose from in Fig. 13. It was decided to use pairs of points that were 3 points apart which represented 36 deg. elec. The results are shown in Figs. 14 and 15. The positional angle is the mean angle between the two points.

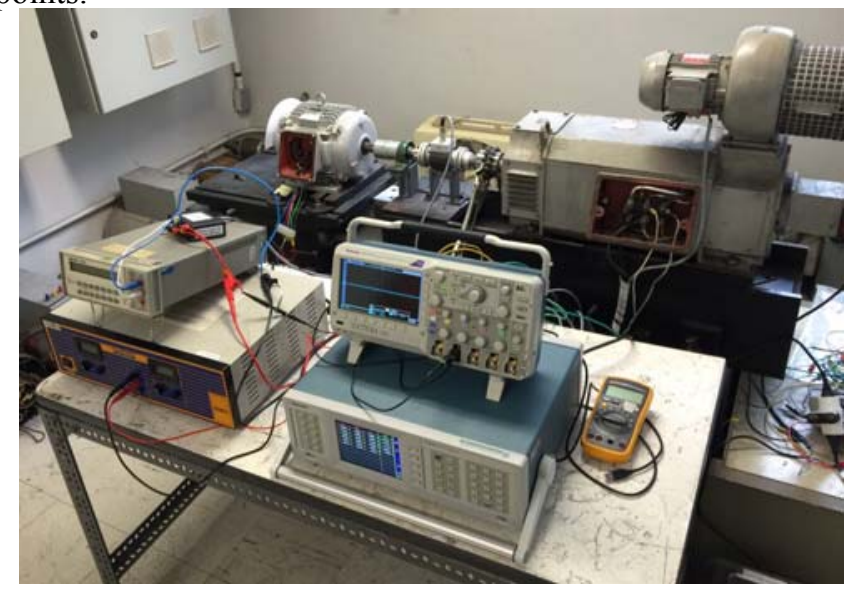

Fig. 12. Second test machine set-up. 


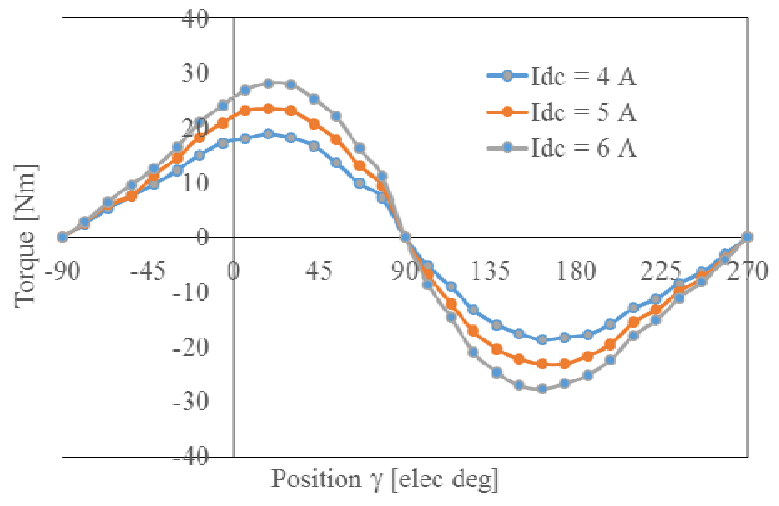

Fig. 13. Torque against $\gamma$ for different dc current levels in second test machine.

What can be seen in Fig. 13 is that the values for $L_{q}-L_{d}$ can be calculated from most of the point pairs however when the torque is going through the zero crossing point the results are unstable. This illustrates that care should be taken when choosing the two points to use when calculating $L_{q}-L_{d}$. Since the machine has $q$-axis saliency then $L_{q}-L_{d}$ is about $60 \mathrm{mH}$.

The magnet flux linkage with one phase is shown in Fig. 15. This shows a flux linkage of about $500 \mathrm{mVs}$. These values were obtained from the characteristic in Fig. 13 using two points per value. As already mentioned, care should be taken in choosing two points. Instability occurs when the torque crosses the zero point suggesting that one point with positive torque, and one point with negative torque should not be used.

To complete the tests, then a slow speed short-circuit test needs to be carried out to calculate $L_{d}$. However, an open circuit test is necessary to obtain the induced emf and validate the calculation of the flux linkage. In Fig. 16 the results from an open circuit test are given. The machine was run up and the open-circuit phase voltages and frequencies were measured. From this figure, the change in voltage is $196 \mathrm{~V}$ (averaged over three phases) and the change in frequency is $57.4 \mathrm{~Hz}$. This gives a magnet flux linkage of $0.54 \mathrm{Vs}$. This matches the results from the calculations in Fig. 15 very well and illustrates the validity of the locked rotor calculations.

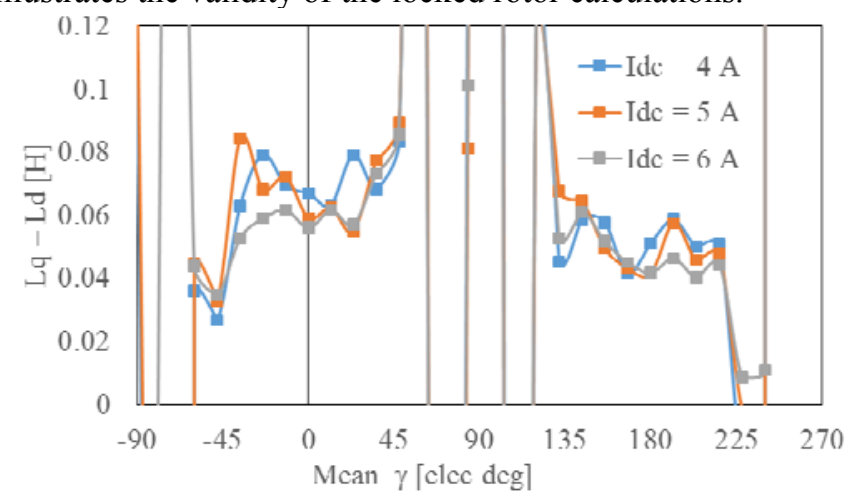

Fig. 14. Calculation of $L_{q}-L_{d}$ from dc test for second test motor.

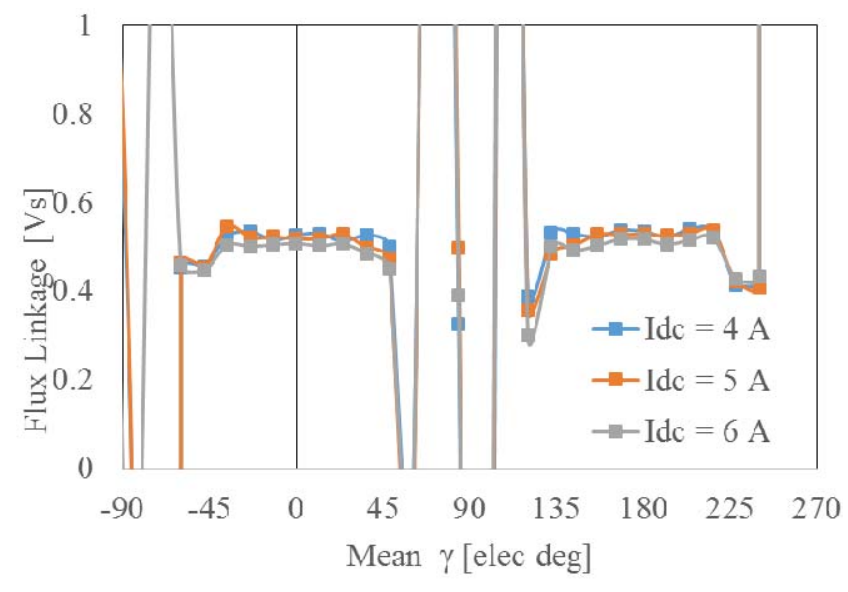

Fig. 15. Calculation of magnet flux linkage from dc tests for second motor.

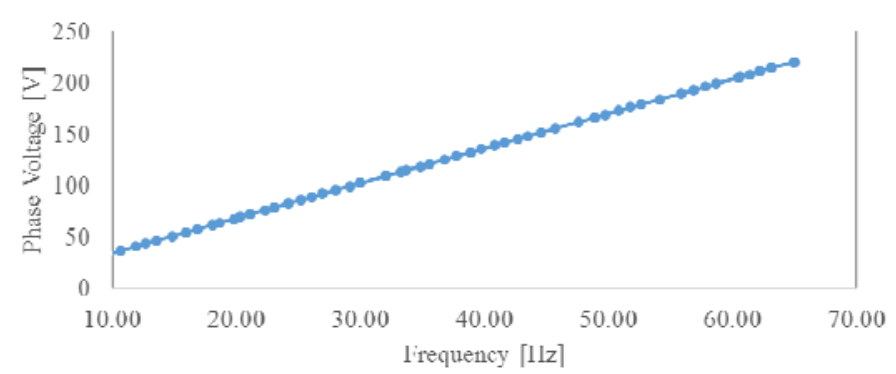

Fig. 16. Open circuit test.

It should be noted that the test results presented in Figs. 6, 8 , and 13 show the measured torque for a complete electrical period which is not strictly needed to get the machine parameters. The parameter values can be obtained only with two different rotor positions, not the entire electrical period. The results for entire electrical period are shown here to highlight to the reader the importance of considering two points to obtain the parameters, as highlighted in Figs. 14 and 15. If two points with discordant torque sign are used to compute PM flux-linkage, an instability in results will occur as illustrated in Fig. 15.

The modified short-circuit tests, i.e. with an external inductance, are given in Table II. Using the induced emfs from Fig. 16 the terminal voltages and currents were measured for three different inductive loads when the rotor was rotated at a speed that produces $60 \mathrm{~Hz}$ frequency. It can be seen that $L_{d}$ is constantly calculated to be about $80 \mathrm{mH}$. Therefore, it follows from the results in Fig. 14 that $L_{q}$ is about $140 \mathrm{mH}$.

TABLE II. SHORT CIRCUIT TESTS TO CALCULATE $L_{D}$ AT $60 \mathrm{~Hz}$

\begin{tabular}{|c|c|c|c|c|c|c|}
\hline $\begin{array}{c}\boldsymbol{E}_{p h}(\mathbf{O} / \mathbf{C}) \\
{[\mathbf{V}]}\end{array}$ & $\begin{array}{c}\boldsymbol{V}_{p h} \\
{[\mathbf{V}]}\end{array}$ & $\begin{array}{c}\boldsymbol{I}_{p h} \\
{[\mathbf{A}]}\end{array}$ & $\boldsymbol{X}_{\boldsymbol{e x}}[\mathbf{\Omega}]$ & $\begin{array}{c}\boldsymbol{X}_{\boldsymbol{d}}+\boldsymbol{X}_{\boldsymbol{e x}} \\
{[\mathbf{\Omega}]}\end{array}$ & $\boldsymbol{X}_{\boldsymbol{d}}[\mathbf{\Omega}]$ & $\boldsymbol{L}_{\boldsymbol{d}}[\mathbf{H}]$ \\
\hline 205 & 158.5 & 1.53 & 103.6 & 134.0 & 30.4 & 0.081 \\
\hline 205 & 166.6 & 1.28 & 130.2 & 160.2 & 30.0 & 0.080 \\
\hline 205 & 182.7 & 0.71 & 257.3 & 288.7 & 31.4 & 0.083 \\
\hline
\end{tabular}




\section{CONCLUSIONS}

The use of brushless permanent magnet machines is ever increasing. This trend, which is likely to continue well into the future, is due to their high torque density and high efficiency compared to their asynchronous counterparts. For high performance and efficient control, a knowledge of their electrical and magnetic parameters is of utmost importance. Simple test methods are desired to speed up the commissioning process; this paper has proposed one such method. The tests investigated here are useful for manufacturers whose goal is to test the machines either at specific load points or over a range of loads, to validate the magnetic design and the manufacturing processes.

Additionally, the presented method will be useful to users who have limited or no information about the machine and where the tests are needed to characterize the machine fully without the need of an inverter drive. In many generator applications, diode bridges are used instead of inverters so that an inverter may not always be available. One of the machines studied here is an IPM generator with $q$-axis saliency and the method gave fairly accurate results for this machine.

\section{REFERENCES}

[1] N. Bianchi, L. Alberti, M. Popescu, T. J. E. Miller, "MMF Harmonics Effect on the Embedded FE-Analytical Computation of PM Motors", IEEE IAS Annual Meeting, 2007, pp 1544-1551.

[2] M. Barcaro, A. Faggion, N. Bianchi and S. Bolognani, "Sensorless Rotor Position Detection Capability of a Dual Three-Phase Fractional-Slot IPM Machine", IEEE Trans. on Ind. Appl., Vol. 48, No. 6, pp 20682078, 2012.

[3] T. J. E. Miller, M. Popescu, C. Cossar, M. McGilp, And J. A. Walker, "Calculating the interior permanent-magnet motor", IEEE IEMDC, 2003, vol. 2, pp 1181-1187.

[4] N. Bedetti, S. Calligaro, R. Petrella, "Stand-Still Self-Identification of Flux Characteristics for Synchronous Reluctance Machines Using Novel Saturation Approximating Function and Multiple Linear Regression", IEEE Trans. on Ind. Appl., Vol. 52, No. 4, pp. 3083-3092, 2016.

[5] S. Yang, K. Lin, "Automatic Control Loop Tuning for PermanentMagnet AC Servo Motor Drives", IEEE Trans. on Ind. Electr., Vol. 63, No. 3, pp. 1499-1506, 2016.

[6] J. A. Walker, Aspects of Magnetization and Iron Loss Characteristics in Switched-Reluctance and Permanent-Magnet Machines, PhD Thesis, University of Glasgow, March 2006.

[7] J. A. Walker, C. Cossar and T. J. E. Miller, "Simulation and analysis of magnetisation characteristics of interior permanent magnet motors," Journal of Advanced Engineering, Acta Polytechnica, vol. 45, no. 4, pp 25-32, 2005.

[8] M. Popescu, D.M. Ionel, T.J.E. Miller, S.J. Dellinger and M.I. McGilp, "Improved finite element computations of torque in brushless permanent magnet motors," Proc. IEE - Elec. Power Appl., Vol. 152, No. 2, pp 271-276, March 2005
[9] H. Kim, J. Hartwig and R. D. Lorenz, "Using on-line parameter estimation to improve efficiency of IPM machine drives", IEEE PESC, 2002, vol. 2, pp 815-820.

[10] D. M. Reed, J. Sun, H. F. Hofmann, "Simultaneous Identification and Adaptive Torque Control of Permanent Magnet Synchronous Machines", IEEE Trans. on Control Systems Techn., IEEE Early Access Article, Vol. --, No. --, pp. --, 2016.

[11] M. S. Rafaq, F. Mwasilu, J. Kim, H. H. Choi, J. W. Jung, "Online Parameter Identification for Model-Based Sensorless Control of Interior Permanent Magnet Synchronous Machine", IEEE Trans. on Power Electr, IEEE Early Access Article, Vol. --, No. --, pp. --, 2016.

[12] J. R. Hendershot and T. J. E. Miller, Design of Brushless Permanent Magnet Motors, Clarendon Press, Oxford, UK, 1994.

[13] D. O'Kelly, Performance and Control of Electrical Machines, McGraw Hill, UK, 1991.

[14] S. A. Odhano, R. Bojoi, M. Popescu, A. Tenconi, "Parameter Identification and Self Commissioning of AC Permanent Magnet Machines - A Review", Proc. of IEEE Workshop on Electrical Machines Design, Control and Diagnosis WEMDCD, pp.195-203, 2015

[15] E. Armando, R. I. Bojoi, P. Guglielmi, G. Pellegrino, and M. Pastorelli, "Experimental Identification of the Magnetic Model of Synchronous Machines," IEEE Trans. on Ind. Appl., vol. 49, pp. 2116-2125, 2013.

[16] I. Omrane, E. Etien, O. Bachelier, and W. Dib, "A simplified least squares identification of permanent magnet synchronous motor parameters at standstill," IEEE IECON, pp. 2578-2583, 2013.

[17] L. Xiao, W. Tao, and F. Wei, "Adaptive parameter identification based on dead-time compensation for Permanent Magnet Synchronous Machines" International Conference on Control, Automation and Systems (ICCAS), 2011, pp. 1570-1575.

[18] S. A. Odhano, P. Giangrande, R. Bojoi, and C. Gerada, "Self-commissioning of Interior Permanent Magnet Synchronous Motor Drives With High-Frequency Current Injection", IEEE Trans. on Ind. Appl., vol. 50, issue 5, pp. 3295-3303, 2014.

[19] S. A. Odhano, R. Bojoi, S. G. Rosu, A. Tenconi, "Identification of the Magnetic Model of Permanent Magnet Synchronous Machines Using DC-biased Low-Frequency AC Signal Injection", IEEE Trans. on Ind. Appl, vol. 51, issue 4, pp. 3208-3215, 2015.

[20] P. H. Mellor, F. B. Chaaban, K. J. Binns, "Estimation of parameters and performance of rare-earth permanent-magnet motors avoiding measurement of load angle", IEE Proc-B - Elec. Power Appl., vol. 138 n. 6 November 1991, pp322-330.

[21] S. A. Odhano, R. Bojoi, E. Armando, G. Homrich, A. F. F. Filho, M. Popescu, D. G. Dorrell, "Parameter Extraction for Three Phase IPM Machines Through Simple Torque Tests", Proc. IEEE Energy Conversion Congress and Exposition, pp. 1892-1898, 2015.

[22] M. Popescu and D. G. Dorrell, “A Method for Determining IPM Motor Parameters from Simple Torque Test Data", IEEE IECON, Vienna, Nov 2013.

[23] E. Armando, P. Guglielmi, G. Pellegrino, M. Pastorelli, A. Vagati, "Accurate Modeling and Performance Analylsis of IPM-PMASR Motors", IEEE Trans. on Ind. Appl., vol. 45, issue 1, pp. 123-130, 2009.

[24] IEEE Standard Test Procedure for Polyphase Induction Motors and Generators," IEEE Std 112-2004 (Revision of IEEE Std 112-1996), pp. 1-79, 2004.

[25] IEEE Standard, IEEE Trial-Use Guide for Testing Permanent magnet machines, 2014 